\title{
OS IMPACTOS DA GERAÇÃO DE EMPREGOS SOBRE AS DESIGUALDADES DE RENDA Uma análise da década de 2000
}

\author{
Flavio Alex de Oliveira Carvalhaes \\ Rogério Jerônimo Barbosa \\ Pedro Herculano G. F. de Souza \\ Carlos Antônio Costa Ribeiro
}

\section{Introdução}

O Brasil tem uma das piores distribuiçōes de renda do mundo. No entanto, nos últimos anos, a desigualdade de rendimentos tem caído sistematicamente (Ferreira e Barros, 1998; Ferreira e Litchfield, 2001; Silva, 2003; Barros et al., 2006b; a; Ferreira et al., 2006). Ao mesmo tempo, desde meados da última década, a retomada do crescimento econômico promoveu forte expansão do assalariamento formal e queda do desemprego (Guimarães, 2012). Esse cenário motiva o questionamento sobre a relação entre esses dois processos, isto é, sobre como as tendências ocupacionais do mercado de trabalho brasileiro se relacionam com a queda das desigualdades. Neste artigo, pretendemos compreender como as desigualdades se relacionam com a estrutura ocupacional e como foram afetadas pela expansão do emprego.

Artigo recebido em 08/11/2012

Aprovado em 26/03/2014
De forma geral, um pesquisador interessado no estudo desse tema tem diante de si dois tipos de estratégia. Na primeira, há um caminho no qual a preocupação central é entender aspectos que estruturam o nível de renda dos indivíduos, basicamente através da associação entre variáveis num modelo multivariado. Um economista destacaria a importância do nível de escolaridade e da experiência do indivíduo (capital humano), além de outros fatores relacionados à produtividade (Becker, 1976). Apesar das diferenças disciplinares, um sociólogo diante do mesmo tema se comporta de forma relativamente parecida. Se estereotipássemos os nossos colegas de profissão como fizemos com os economistas, o destaque iria para o papel da estrutura ocupacional e de fatores adscritos ou "herdados" (raça, sexo). Tanto na literatura internacional quanto na brasileira, contamos com excelentes estudos sobre o tema (Blau e Duncan, 1967; Wright, 1997; Santos, 2002; Neves, 2005). 
Uma segunda estratégia seria tratar a desigualdade como um "estoque" distribuído entre unidades de análise (cidade, país, classes, ocupações etc.), para então distinguir os aspectos sistemáticos dos não sistemáticos desse fenômeno. Nesse caso, o pesquisador está interessado no "tamanho" do componente sistemático e qual parcela da variação não é explicada por nenhum dos fatores considerados. Economistas criaram importantes métodos para decompor indicadores sintéticos de desigualdade de renda (Knight e Salbot, 1983; Lemieux, 2006; Tavares e Menezes-Filho, 2011). Nesse tipo de estratégia de pesquisa, a sociologia, tanto internacional quanto nacional, está defasada (Morris e Western, 1999), apesar de algumas iniciativas recentes terem importantes ganhos analíticos (Weeden, 2002; Weeden et al., 2007; Kim e Sakamoto, 2008; Mouw e Kalleberg, 2010).

Lançaremos mão dos dois tipos de estratégias. Utilizando modelos de decomposição baseados em regressões (Western e Bloome, 2009), temos condiçôes tanto de entender quais são os fatores mais importantes na estruturação da renda nos anos estudados como de decompor nossa distribuição. Ressaltamos que a literatura sociológica brasileira sobre o tema é praticamente inexistente, mesmo sendo o Brasil um caso privilegiado para esse tipo de estudo. Pretendemos atuar nesse espaço identificado pelas análises sobre a tendência da desigualdade de renda no país e assim complementar os trabalhos já feitos. De maneira mais direta, a principal pergunta que propomos responder é a seguinte: que parcela da desigualdade de renda se deve especificamente às características estruturais, entendidas como o aspecto ocupacional, do mercado de trabalho?

Para realizar nossa investigação seguimos dois passos. Primeiramente examinamos a qualidade relativa dos postos de trabalho criados entre 2002 e 2012. Em seguida, tendo mapeado o padrão de evolução do emprego, investigamos mais detidamente a relação entre a estrutura ocupacional e a desigualdade de renda do trabalho.

O texto está organizado em seis partes, incluindo esta introdução. Na próxima, fazemos um breve histórico das tendências de desigualdade de renda no mercado de trabalho. Apresentamos, então, as principais questões teóricas e metodológicas que informam nossa análise. $\mathrm{Na}$ sequência, descrevemos o padrão de expansão do emprego na última década e, a seguir, investigamos que parcela das desigualdades de renda pode ser explicada pelas características da estrutura ocupacional. A partir dessa informação, mensuramos a influência que as mudanças na estrutura ocupacional exerceram sobre a tendência de declínio das desigualdades de renda ao longo do tempo. Por fim, apresentamos algumas conclusões e discussões mais gerais.

\section{Desigualdades no mercado de trabalho}

Ao longo das últimas três décadas, a conjuntura econômica nacional teve alterações importantes. $\mathrm{O}$ ano de 1981 inaugurou um período de profunda instabilidade macroeconômica. Tais flutuações foram captadas pelos indicadores de distribuição de renda e o saldo foi um crescimento considerável da desigualdade. Entre 1989 e 1991, todos os índices registram os maiores patamares de desigualdade da história recente. A partir de 1994, esses indicadores apontam lenta melhoria da distribuição de renda; mas apenas após 2001 o declínio se torna consistente e acentuado. Desde então, vem se tornando claro que esse movimento de queda pode ser duradouro.

A dificuldade de detectar as causas desse movimento reside no fato de que uma série de outras transformações demográficas, econômicas e sociais ocorreu paralelamente à queda da desigualdade. A literatura especializada tentou isolar os principais fatores para o declínio da desigualdade de renda e atribuir-lhes pesos e importâncias diferenciais; dois deles são a estabilização macroeconômica e o controle da inflação (Ferreira e Litchfield, 2001; Barros et al., 2006b; Ferreira et al., 2006). No entanto, também ficou claro que apenas o crescimento econômico não poderia ser responsável pela distribuição da renda. As mudanças na escolaridade da população revelaram-se fundamentais, e seus efeitos mais importantes foram (1) a ampliação do acesso aos níveis mais baixos de ensino e (2) o declínio significativo dos diferenciais de remuneração da força de trabalho por nível de escolaridade. Esse movimento da educação explicaria $40 \%$ da queda da desigual- 


\section{Gráfico 1 \\ Evolução da desigualdade da renda do trabalho segundo os índices de Gini, Theil e a Variância do Logaritmo da Renda (1981-2009)}

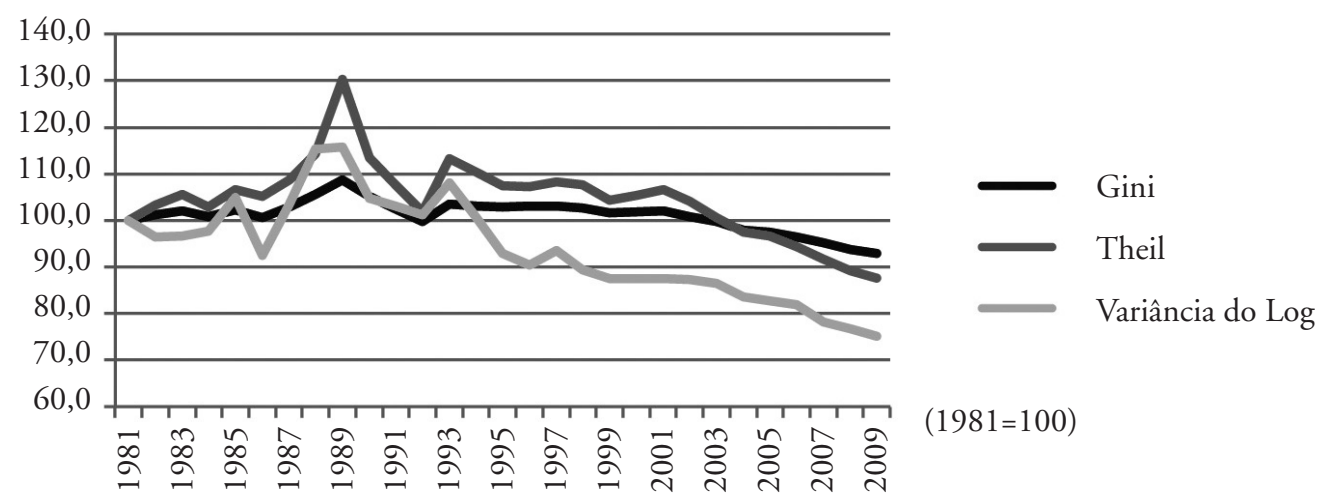

Fontes: PNAD, 1981-2009 (elaboração própria).

dade da renda do trabalho entre 2001 e 2005. Sublinha-se também a importância de alterações nos componentes demográficos, como a homogeneização etária da população, que reduz os retornos pela experiência (Barros et al., 2006a), e a convergência entre rendimentos dos setores rurais e urbanos (Ferreira et al., 2006). Grosso modo, essas foram algumas das características destacadas pela literatura que analisou o declínio da desigualdade de renda brasileira, especialmente a partir de 2003, quando ele se acelera (Lemieux, 2006; Tavares e Menezes-Filho, 2011).

\section{Por que ocupaçóes?}

Do ponto de vista sociológico, a principal ressalva à abordagem econômica do estudo da desigualdade de renda é a excessiva ênfase nas características individuais e a falta de sensibilidade a dimensões institucionais. Classicamente, a sociologia se propõe a compreender como características individuais interagem com aspectos estruturais da divisão do trabalho (Sorensen, 1996; Acemoglu, 2002; Autor, Katz e Kearney, 2006). Uma das formas privilegiadas de realização desse empreendimento seria através da atenção especial à dimensão ocupacional. E essa dimensão importa de várias maneiras.
As ocupações variam no nível de habilidade requerido para realizá-las - ou seja, o grau e complexidade das atividades e o tempo necessário para aprendê-las. Além disso, as habilidades e qualificações exigidas no trabalho são recompensadas diferentemente em cada segmento ocupacional (Mouw e Kalleberg, 2010). Credenciais educacionais, por exemplo, são valorizadas diferentemente em cada ocupação - ou seja, assumimos os retornos educacionais interagem com a posição no mercado de trabalho.

Outro ponto diz respeito aos mecanismos que definem o grau de abertura ou fechamento. Ocupaçôes menos especializadas e mais abertas à substituição de trabalhadores, seriam menos protegidas e mais sujeitas às flutuações da oferta de mão de obra; enquanto ocupaçōes mais especializadas (em que há maior interdependência na cadeia produtiva, escassez de profissionais e altos custos para formação) teriam outro tipo de dinâmica, sendo mais fechadas à substituição (Sorensen e Kalleberg, 1979). Ocupações distintas têm diferentes marcos regulatórios e podem ou não ter conselhos e associações que protegem seus interesses e executam ações de licenciamento, certificação, sindicalização etc. Tais instituiçōes estão diretamente ligadas às estruturação das desigualdades no mercado de trabalho e operam como verdadeiros mecanismos de fechamento social (Grusky e Soren- 
sen, 1998; Weeden, 2002; Grusky e Galescu, 2005; Grusky e Weeden, 2008).

Além disso, a estrutura ocupacional é uma forma privilegiada para a compreensão das características da renda permanente dos indivíduos (expectativa de rendimentos durante todo o curso de vida), que está correlacionada tanto aos modos de vida como às possibilidades de mobilidade social (Weeden, 2002; Kim e Sakamoto, 2008; Liu e Grusky, 2013). A intuição básica é de que haveria uma relativa homogeneidade nas chances de vida de indivíduos pertencentes à mesma classe. Sendo a ocupação um indicador privilegiado da posição de classe, a inserção dos indivíduos no mercado de trabalho torna-se indispensável para entender como a desigualdade se organiza, considerando até os fatores institucionais que diferenciam as ocupações entre si.

O peso dado às ocupações é complementar a outras perspectivas amplamente acionadas na literatura sobre desigualdade de renda. Assim, não desejamos negar, por exemplo, a importância de dimensōes relativas ao nível de escolaridade da população. Em nossas avaliações, estamos atentos a esses processos e ao balanço de sua relevância em relação aos fatores ocupacionais.

Feita essa caracterização analítica sobre a importância das ocupações e outras dimensões no entendimento da desigualdade de renda, podemos explicitar um pouco melhor como pretendemos realizar nossos exercícios empíricos. Nosso primeiro passo é examinar as dinâmicas de expansão dos postos de trabalho na última década. Seguindo Wright e Dwyer (2003), compreendemos que há padrões de geração de emprego. Se ordenarmos os postos de trabalho existentes (ocupaçōes) segundo algum critério de qualidade (numa escala que leva dos "piores" aos "melhores" empregos), podemos nos questionar onde os novos empregos se encaixam nessa escala. Há ao menos quatro cenários possíveis: 1) expansão igualmente distribuída entre todos os tipos de emprego; 2) expansão apenas dos piores empregos; 3 ) crescimento dos melhores empregos; 4) expansão polarizada (na qual empregos de nível intermediário crescem menos ou até decrescem, gerando um "abismo" entre os ocupantes dos piores e dos melhores cargos). Trataremos de cada uma dessas possibilidades com mais detalhes adiante. Cabe antes indagar: qual modelo melhor descreve o caso brasileiro na última década? E de que forma os padrões de geração de emprego se relacionam à dinâmica das desigualdades? Em nosso segundo passo analítico, estabelecemos mais precisamente os formatos dessa relação. Partindo de uma decomposição da variância do logaritmo natural da renda do trabalho (uma medida clássica de desigualdade), obtemos três efeitos que relacionam a desigualdade de renda do trabalho às ocupações (idem; Williams, 2010).

O primeiro deles é o chamado efeito de composição. Ele está relacionado à proporção de trabalhadores ligados a uma categoria ocupacional. Por exemplo, se uma ocupação na qual há muita desigualdade entre amplia seu tamanho relativo, isso contribui para o aumento da desigualdade global no mercado de trabalho. Inversamente, se uma ocupação em que há maior igualdade salarial amplia sua proporção, os níveis gerais de desigualdade decrescem. Desse modo, o efeito de composição diz respeito ao movimento causado pelas alteraçôes na distribuição dos indivíduos entre ocupaçôes, por sua vez provocado pelo crescimento ou pelo encolhimento dos grupos.

O segundo fator, chamado efeito de médias, refere-se a mudanças nos salários médios das ocupações. O ganho real médio dos salários tende a variar de ocupação para ocupação. Desequilíbrios entre oferta e demanda, ou fatores institucionais, como a atuação dos sindicatos na renegociação salarial, são exemplos de mecanismos que podem fazer os salários médios das ocupações variarem positiva ou negativamente ao longo do tempo. $\mathrm{O}$ efeito de médias é, portanto, o saldo nos índices de desigualdade provocado pela aproximação ou pelo distanciamento dos salários entre ocupações.

O terceiro fator diz respeito a como se comporta a distribuição da renda no interior das ocupaçôes, ou seja, a desigualdade entre indivíduos dentro das ocupações, a desigualdade intraocupacional - também chamada de desigualdade residual, pois descreve a dispersão dos rendimentos que persiste após a introdução dos indicadores dos grupos ocupacionais e de outras variáveis de controle. Um possível motivo para a elevação da desigualdade intraocupacional pode ser o aumento do retorno em 
rendimentos ligado a características individuais não observadas (isto é, não ligadas às ocupações e aos controles explicitamente incluídos nos modelos). O termo desigualdade residual, porém, não é plenamente adequado, uma vez que a maior ou menor dispersão dos salários dentro das ocupações pode ser, ela mesma, uma característica estrutural da ocupação (Western e Bloome, 2009); uma maior dispersão indica uma heterogeneidade constitutiva da ocupação, ao passo que uma maior homogeneidade pode indicar presença de instituições e normas típicas de profissões regulamentadas ou empregos públicos. Desse modo, entendemos que a distribuição dos salários dentro das ocupações é essencialmente heterocedástica.

\section{Estratégias analíticas, metodologia e dados}

\section{Padrôes de geração do emprego e decomposição das desigualdades}

Para analisar a qualidade dos empregos criados na década de 2000, seguiremos uma estratégia elaborada por Wright e Dwyer (2003). Nesse trabalho, os autores propõem a criação de uma matriz de cruzamento entre categorias ocupacionais e setores de atividade. Esse exercício produz um total de "empregos em potencial”, representado pelo número de células da matriz - cada uma representa uma ocupação-setor, que pode ou não estar preenchida (por isso, "potencial"). ${ }^{1}$ Em seguida, ordenam-se as células de acordo com a mediana da renda do trabalho, considerada proxy da "qualidade do emprego". Por fim, as ocupaçôes-setor são divididas em cinco grupos - quintos - de acordo com essa medida. Os indivíduos de uma mesma ocupação-setor são levados "em bloco" para uma única categoria. Temos assim uma escala de qualidade dos empregos, com cinco pontos, cada um com $20 \%$ dos indivíduos empregados. Como cada ocupação-setor tem posição fixa nesse ordenamento, acompanhar o crescimento ou decrescimento de um quinto é observar quanto variou o número de empregados nas ocupaçóes-setor entre dois pontos no tempo. A variação do emprego em cada quinto é medida simplesmente pela diferença absoluta no tamanho dessas categorias entre o ano final e o inicial de mensuração. $\mathrm{O}$ resultado é uma medida do saldo de emprego (ou mudança líquida no estoque de trabalhadores) que considera a qualidade dos postos criados e desfeitos.

Figura 1

Quatro modelos hipotéticos de variação dos quintis

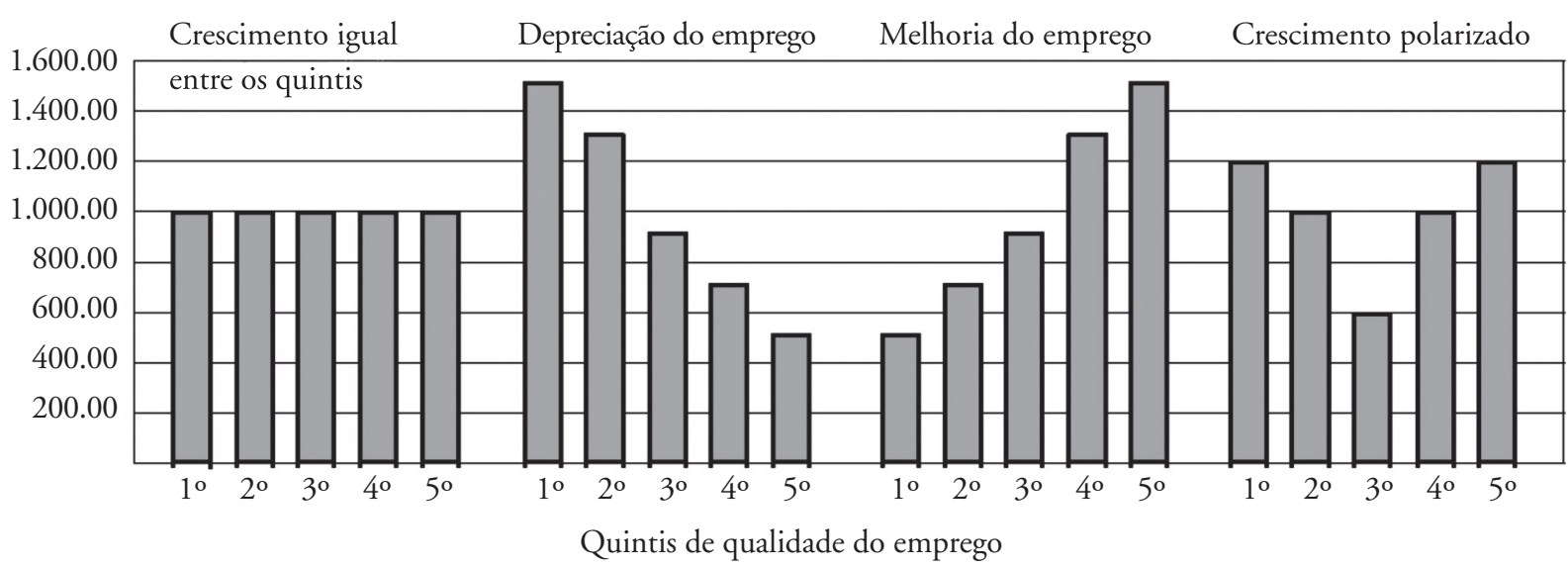

Ilustração baseada no modelo do artigo de Wright \& Dwyer (2003). 
Como pontuamos na seção anterior, os resultados desse exercício podem se concentrar, a princípio, em quatro modelos de variação do tamanho dos quintos, que representam padrôes distintos de expansão do emprego e cujas consequências, em termos de desigualdades sociais, podem ser completamente opostas. A figura 1 ilustra esses cenários hipotéticos para uma situação que tenha gerado 5 milhões de empregos.

O primeiro modelo apresenta um crescimento igual dos quintos, de 1 milhão de empregos, e a estrutura anterior do mercado de trabalho não se altera de maneira significativa. Supostamente, esse quadro estaria ligado à manutenção do estado das desigualdades ocupacionais. No segundo modelo, observamos um crescimento mais acentuado das ocupações de baixo nível, o que reflete um contexto de depreciação do emprego. Com a geração de emprego concentrada nos postos de baixa remuneração, assistimos ao aumento da pobreza e possivelmente das desigualdades. $\mathrm{O}$ terceiro modelo apresenta a situação oposta: há expansão principalmente dos postos de melhor qualidade. Esse cenário de "melhoria de emprego" (job upgrading, no termo original) não tem interpretação consensual, no entanto. No fim da década de 1990 e início dos anos de 2000, alguns economistas supunham que ele era sintomático do desenvolvimento econômico baseado na inovação tecnológica e gerencial. Os mercados de trabalho responderiam através da ampliação da demanda por trabalhadores mais qualificados, por sua vez acompanhada da redução da procura por ocupações de baixa qualificação (Acemoglu, 2002). Essa interpretação foi denominada skill-based technological change (SBTC) e descreveria bem o quadro dos anos de 1960 nos Estados Unidos (Wright e Dwyer, 2003). Esse movimento seria positivo: reduziria as desigualdades, no médio prazo. O caso brasileiro, no entanto, traz um contraexemplo. A explicação de Langoni (2005) para a elevação das desigualdades durante o período militar se baseia justamente no fato de que a elevação da demanda por trabalhadores qualificados gerou disparidades salariais muito intensas. Diante da escassez de capital humano, os poucos indivíduos com capacidade de suprir essa demanda foram premiados de forma desproporcional. Desse modo, não é tácito que melhoria de emprego seja sinônimo de redução de desigualdades - aliás, um de nossos objetivos é justamente contrapor o formato de geração do emprego ao movimento dos indicadores de desigualdade.

O último modelo representa uma situação híbrida - em que há a criação simultânea de bons e maus empregos - que gera um contexto de polarização do mercado de trabalho, com o potencial aumento da desigualdade. Essa conjuntura se tornou bastante discutida em trabalhos de economistas norte-americanos e europeus (Autor, Levy e Murnane, 2003; Manning, 2003; Goos e Manning, 2007; Goos, Manning e Salomons, 2009), pois fornecia uma boa explicação para a crescente desigualdade de rendimentos ocorrida a partir da década de 1980 nesses países. Autor, Levy e Murnane (2003) argumentam que a inovação tecnológica e a consequente automação levariam ao decréscimo da demanda por trabalhos de rotina, manuais (por exemplo, industriais) e não manuais (realizados em escritório). A demanda baseada em tecnologia ainda é o fundamento da explicação. Ocupações altamente qualificadas (que envolvem atividades gerenciais, analíticas ou criativas), bem como manuais de baixa qualificação (limpeza, serviços pessoais etc.) não seriam facilmente substituídas pela tecnologia. Como os empregos de rotina se situam no meio da distribuição salarial, seu desaparecimento faria com que a geração de empregos assumisse um formato polar. Corroborando essa leitura baseada na centralidade da tecnologia e do capital humano, Goldin e Katz (2008) afirmam que, nos Estados Unidos, a expansão educacional trouxe igualdade salarial e redução dos retornos pela educação até os anos de 1970, reduzindo a desigualdade total. A partir de então, o processo se inverte e há retornos crescentes pela educação.

Em contraponto aos economistas, os sociólogos elencam fatores não produtivos ligados à polarização. Wright e Dwyer (2003) apontam que a composição da força de trabalho (por raça, sexo, status de imigração etc.) é um aspecto central: grupos de menor status ocuparam a base da estrutura polar. Para DiPrete et al. (2006), Kalleberg (2012) e Mouw e Kalleberg (2010), o fenômeno esteve ligado à dinâmicas ocupacionais - voltaremos ao 
argumento desses autores adiante. Fernandez-Macíaz (2012) e Oesch e Menés (2012) mostram que a regulação estatal e características institucionais são determinantes para as condições de polarização - e também para as direções das tendências de distribuição e desigualdade de rendimentos. Independentemente da interpretação de suas causas, é consensual que o quadro polarizado eleva as desigualdades.

A análise gráfica desses resultados permite-nos avaliar apenas de maneira descritiva e qualitativa o formato da expansão do emprego na década de 2000. A segunda etapa de nossas análises dedica-se justamente à avaliação da relação entre a estrutura ocupacional e a desigualdade de renda. O objetivo é responder às seguintes questões:

- Caso tenha havido alteração substantiva na distribuição (tamanho) das ocupaçōes, em que medida esse movimento afetou a redução das desigualdades.

- Em que medida a mudança do padrão da média entre as ocupaçôes dos salários levou à redução das desigualdades.

- Se as ocupações teriam pouca importância e a maior parte do declínio se deveria à redução das desigualdades entre indivíduos dentro das ocupaçôes, ou seja, a fatores intraocupacionais/ não observáveis.

Estas três questões não são antagônicas, mas complementares, e todos os movimentos podem ter acontecido conjuntamente. Nesse sentido, nosso objetivo é indicar e mensurar qual a importância relativa de cada um.

$\mathrm{Na}$ tentativa de explicar o fenômeno da polarização das ocupações nos Estados Unidos, já observado em estudos anteriores, Mouw e Kalleberg (2010) propuseram analisar o movimento das desigualdades por meio de decomposição, a partir de modelos de regressão (Western e Bloome, 2009). Trata-se de uma forma de ligar o debate sobre a mudança no padrão de emprego à pesquisa sobre a desigualdade de renda e os seus vários determinantes: educação, estrutura ocupacional, raça, gênero etc. Por isso, adotamos estratégias semelhantes para o caso brasileiro.
Partimos da simples decomposição da variância do logaritmo da renda condicional a categorias ocupacionais:

$$
\begin{array}{ll}
\operatorname{Var}\left[\ln \_ \text {renda } \mid \text { ocup }\right]_{\mathrm{t}}= & \sum_{j} p_{j t}\left(\mu_{j t}-\bar{\mu}_{t}\right)^{2}+\sum_{j} p_{j t} \sigma_{j t}^{2} \\
\text { Desigualdade total } & =\begin{array}{ll}
\text { Desigualdade } & \text { Desigualdade } \\
\text { interocupacional } & \text { intraocupacional } \\
\text { (entre indivíduos) }
\end{array}
\end{array}
$$

A fórmula 1.1a traz a decomposição da variância do logaritmo da renda do trabalho ${ }^{2}$ em dois termos, que representam a desigualdade entre e dentro das ocupações. Em outros termos, $V_{\text {total }}=V_{\text {intra }}+V_{\text {entre }} \cdot p_{j t}$ representa a proporção de ocupados no grupo ocupacional $j$ no ano $t ; \mu_{j t}$ representa a renda média da ocupação $j$ no ano $t$; $\overline{\mu_{t}}$ representa a média de todos os salários (grande média) no ano $t$. Assim, no primeiro termo, se uma ocupação dista muito da grande média (para mais ou para menos), essa distância é elevada ao quadrado e, por isso, contribui (de forma proporcional ao seu tamanho) para o aumento geral da desigualdade. No segundo termo, $\sigma_{j t}^{2}$ representa a variância do logaritmo da renda do trabalho no interior da ocupação $j$ no ano $t$. Ou seja, a desigualdade no interior de um grupo ocupacional contribui para o aumento da desigualdade geral (de maneira também proporcional ao tamanho). Essa equação mostra que o total de desigualdade num determinado ano pode ser decomposto como a soma da desigualdade entre ocupaçôes e da desigualdade entre indivíduos dentro das ocupações (desigualdade intraocupacional).

Um desenvolvimento adicional da mesma equação ainda permite uma decomposição dinâmica que mede como a desigualdade de renda evoluiu entre dois períodos de tempo. Para isso, é preciso primeiro simplificar a expressão 1.1a. Seguindo Western e Bloome (2009), podemos fazer $r_{j t}^{2}=\left(\mu_{j t}-\overline{\mu_{t}}\right)^{2}$. Então obtemos:

$$
V_{t}=\sum_{j} p_{j t}\left(r_{j t}^{2}+\sigma_{j t}^{2}\right)
$$


A diferença na desigualdade de rendimentos entre dois pontos do tempo ( 0 e $t)$ será dada por:

$$
V_{t}-V_{0}=\sum_{j} p_{j t}\left(r_{j t}^{2}+\sigma_{j t}^{2}\right)-\sum_{j} p_{j 0}\left(r_{j 0}^{2}+\sigma_{j 0}^{2}\right)
$$

Com um pouco de álgebra, podemos reescrever a expressão da seguinte maneira:

$$
\begin{aligned}
V_{t}-V_{0}= & \sum_{j}\left(p_{j t}-p_{j 0}\right)\left(r_{j t}^{2}+\sigma_{j t}^{2}\right) \\
& +\sum_{j} p_{j 0}\left(r_{j t}^{2}-r_{j 0}^{2}\right)+\sum_{j} p_{j 0}\left(\sigma_{j t}^{2}-\sigma_{j 0}^{2}\right)
\end{aligned}
$$

A expressão $1.2 \mathrm{~b}$ mostra que a variação total da desigualdade pode ser decomposta em três efeitos, sobre os quais já tratamos. O primeiro está ligado à variação da proporção das ocupações; por isso é chamado efeito de composição $\left(\Delta_{C}\right)$. O segundo refere-se à distância entre os grupos; assim, é a operacionalização do efeito de médias $\left(\Delta_{M}\right)$. Por fim, o terceiro diz respeito à mudança na dispersão dos salários interna às ocupações; o chamaremos de componente de efeito da variância $\left(\Delta_{V}\right)$. Os três componentes respondem diretamente às questôes anteriormente enunciadas nesta seção. Simplificando, a variação total da desigualdade entre dois períodos de tempo é igual à soma dos três efeitos:

$$
V_{t}-V_{0}=\Delta_{C}+\Delta_{M}+\Delta_{V}
$$

É importante pontuar ainda que uma tendência geral de declínio das desigualdades não significa que todas as ocupações tiveram contribuição idêntica sobre esse movimento. A tendência pode ser decrescente em média, mesmo que algumas ocupaçóes tenham contribuído para o aumento da desigualdade (tendo seus efeitos contrabalanceados por outras).

As equações 1.1 a 1.3 , no entanto, fazem uso apenas de variáveis ocupacionais para decompor as desigualdades, sem qualquer tipo de controle a partir de outras características. Sabe-se que os retornos em rendimentos estão condicionados a outros fatores, como gênero, raça, idade, educação etc. Para identificar o componente especificamente devido às ocupações, aplicamos um método de decomposição baseado em regressões (Mouw e Kalleberg, 2010). Inicialmente, estimamos a média e a variância da renda de cada ocupação controlando pelas variáveis típicas de estudos sobre determinação e desigualdade de renda, como sexo, cor, nível de escolaridade, entre outras (detalhadas adiante). Os componentes são estimados por modelos de regressão que têm os controles como variáveis independentes.

$$
\begin{aligned}
\ln (\text { renda })_{i j t}= & \sum_{j} \alpha_{j t} \text { ocup }_{i j t}+\sum_{k} \beta_{k t} x_{i k t} \\
& +\varepsilon_{i j t}, \varepsilon_{i j t} \sim\left(0, \sigma_{j t}^{2}\right)
\end{aligned}
$$

A expressão 2.1 representa uma regressão linear que traz um conjunto de $j$ variáveis dummy para as ocupações $\left(\right.$ ocup $\left._{i j}\right)$ e também um conjunto de variáveis de controle $\left(x_{i j}\right){ }^{3}$ A equação exclui o termo constante, uma vez que todas as dummies de ocupação serão incluídas. O procedimento de decomposição requer que todos os controles sejam variáveis categóricas. Os controles que introduzimos foram raça (categorizada como "brancos" e "não brancos" $)^{4}$; idade (em grupos de cinco anos), regióes do Brasil (Norte, Nordeste, Centro-Oeste, Sudeste e Sul) e escolaridade (sem instrução, primário incompleto, primário completo/fundamental incompleto, fundamental completo/médio incompleto, médio completo/superior incompleto e superior completo). Os coeficientes $\alpha_{j}$ trazem os efeitos fixos de cada ocupação, ou seja, a parcela da média da renda que se deve às ocupações, abstraída dos controles; $\varepsilon_{i j}$ é o termo de erros heterocedásticos.

Os valores de $\alpha_{j}$ substituirão os de $\mu_{j t}$ nas expressões 1.1 e $1.3,5$ quando estivermos tratando do modelo com controles. Também é necessário estimar a variância do logaritmo da renda dentro de cada ocupação levando em conta as variáveis de controle. Os resíduos da regressão 2.1 representam a parcela de variação não explicada pelas ocupações e pelas demais variáveis. Se os tomarmos em conjunto, tratamos de toda a variância não explicada e não apenas daquela interna às ocupaçôes. Para estimar a parcela que se deve à variância interna de cada ocupação, aplicamos uma regressão em que os resíduos ao quadrado são a variável dependente, utilizando as mesmas variáveis independentes do 
modelo anterior. Por definição, os resíduos ao quadrado são dados por:

$e_{i j t}^{2} \equiv\left[\ln (\text { renda })_{i j t}-\left(\sum_{j} \alpha_{j t} o c u p_{i j t}+\sum_{k} \beta_{k t} x_{i k t}\right)\right]^{2}$

Desse modo, é preciso salvar os resíduos da primeira regressão, elevá-los ao quadrado e submetê-los a um modelo linear com as mesmas variáveis explicativas, conforme a expressão seguinte:

$$
e_{i j t}^{2}=\sum_{j} \delta_{j t} o c u p_{i j t}+\sum_{k} \phi_{k t} x_{i k t}+\omega_{i j t}
$$

Como os resíduos têm média zero, com a equação acima estaremos calculando a sua variância condicional. ${ }^{6} \mathrm{O}$ coeficiente $\delta_{j}$ expressa a parcela dos resíduos que se deve especificamente às ocupaçōes, isto é, à variância intraocupacional, líquida, das variáveis independentes, e assim substitui $\sigma_{j t}^{2}$ nos modelos de decomposição que incluem os controle.

$$
\begin{aligned}
\operatorname{Var}\left[\ln \_ \text {renda } \mid \text { ocup, } \mathrm{X}\right]_{\mathrm{t}}= & \sum_{j} p_{j t}\left(\alpha_{j t}-\overline{\alpha_{t}}\right)^{2} \\
& +\sum_{j} p_{j t} \delta_{j t}
\end{aligned}
$$

A expressão 3.1 é a versão com controles da decomposição fornecida pela expressão 1.1. Apresentaremos os resultados do modelo nulo, sem controles, bem como os de um modelo incluindo apenas os controles de raça, sexo, região e idade, e ainda do modelo completo, que acrescenta escolaridade a esses controles. Esses procedimentos permitem abstrair a importância das variáveis individuais e observar como a mudança de efeitos trazida pela introdução de controles evidencia mediações entre as variáveis, aumenta o poder explicativo e traz maior entendimento para o fenômeno da queda das desigualdades.

\section{Padronização dos dados e procedimentos analíticos}

Nossa fonte de informação são os dados da Pesquisa Nacional por Amostragem de Domicílios
(PNAD) para os anos de 2002 a 2012. Utilizamos estratégias diferentes para a análise da expansão do emprego e para a avaliação da relação entre estrutura ocupacional e desigualdade de renda. $\mathrm{O}$ tratamento preliminar dos dados e a padronização de variáveis são comuns às duas estratégias.

$\mathrm{Na}$ padronização dos dados procedemos da seguinte maneira: removemos os casos com informação incompleta para UF, idade, ocupação, setor, renda do trabalho principal, situação censitária (urbano/rural). Selecionamos apenas indivíduos ocupados na semana de referência e que possuíam entre 25 e 65 anos de idade. Casos com renda igual a zero foram desconsiderados (a renda do trabalho principal da semana de referência é nossa medida de rendimento em todas as análises). Aplicamos o Índice Nacional de Preços ao Consumidor (INPC) para deflacionar as rendas até valores de setembro de 2012 (data da última PNAD analisada). De 2004 em diante, não analisamos os casos de pessoas residentes na zona rural da região Norte - área que não era coberta pelas PNADs de 2002 e 2003 (o percentual de indivíduos excluídos é muito baixo e não afeta a representatividade das análises). O sistema de classificação ocupacional e setorial é o mesmo em todos os anos considerados. Utilizamos uma agregação das ocupaçōes com três dígitos e dos setores econômicos com dois dígitos. Para maximizar a comparação, excluímos ainda as ocupações cujos códigos não se repetiram em todos os anos.

$\mathrm{Na}$ análise dos padrões de geração de emprego, primeiro fundimos todos os bancos de dados calculamos a média ${ }^{7}$ da renda do trabalho principal para cada ocupação-setor. ${ }^{8} \mathrm{O}$ rendimento médio do período todo (2002-2012) é um indicador da "renda permanente" da ocupação e, por isso, mais estável. A partir desse valor, ordenamos as ocupaçōes-setor $\mathrm{e}$ as dividimos em quintos (grupos ordenados que agregam $20 \%$ dos indivíduos empregados). Desse modo, a posição relativa da ocupação-setor diz respeito às suas características médias no período. Uma ocupação-setor não muda de quinto ao longo dos anos - ainda que possa experimentar ganhos ou perdas salariais. Com essa estratégia, nos blindamos contra flutuaçōes conjunturais e imprecisōes amostrais. No entanto, cabe ressaltar que os resultados 
permanecem praticamente idênticos se adotamos uma estratégia que permite a movimentação dos grupos. A avaliação do saldo de geração do emprego por quintos é dada simplesmente pela diferença de frequências em dois períodos. Comparamos os quintos sempre por biênios.

$\mathrm{Na}$ análise de decomposição, utilizamos modelos de regressão por mínimos quadrados para estimação tanto dos coeficientes $\alpha_{j t}$ como $\delta_{j t}$, isto é, tanto nas regressões da média, como dos resíduos. ${ }^{9}$ Todas as análises foram realizadas com o uso do software $\mathrm{R}$, e os códigos completos para a replicação podem ser requisitados aos autores. Os bancos de dados encontram-se disponíveis no site do Centro de Estudos da Metrópole (www.fflch.usp.br/centrodametropole).

\section{Resultados}

Padrôes de expansão do emprego

Não analisamos aqui a composição específica de cada quinto de ocupações-setores. Interessa-nos apenas apresentar o quadro geral do padrão de geração de empregos na década de 2000. Cabe ressaltar que, de modo geral, os quintos de qualidade do emprego têm sempre características específicas. Os mais baixos agrupam um menor número de ocupaçôes-setor, que empregam uma grande quantidade de indivíduos. À medida que avançamos para os quintos superiores, há um número cada vez maior de ocupações-setor; são categorias mais heterogêneas e com maior variabilidade em termos de renda.

Gráficos 2

Padróes de geração de emprego na década de 2000 (saldos bienais)

a) $2002 / 3$ a $2004 / 5$

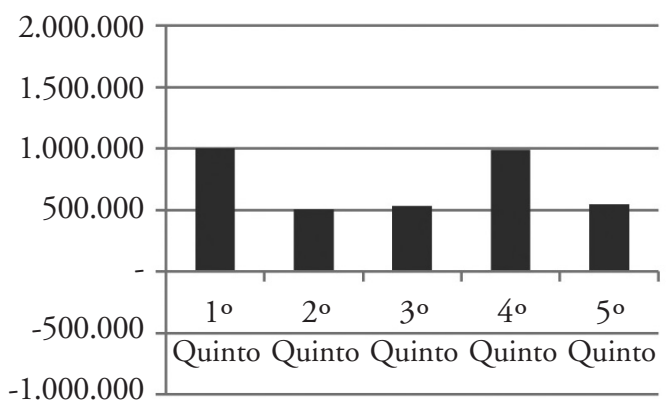

c) $2006 / 7$ a $2008 / 9$

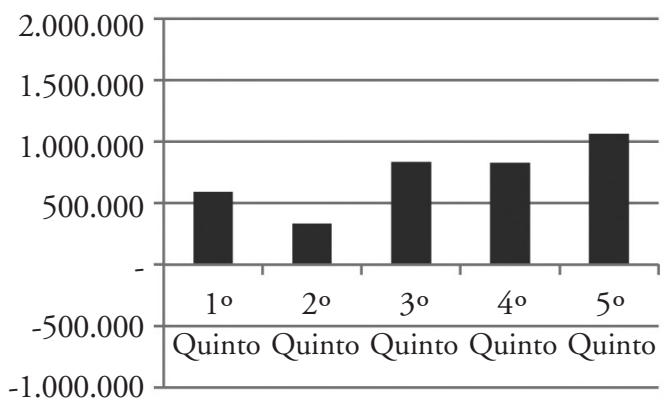

b) $2004 / 5$ a $2006 / 7$

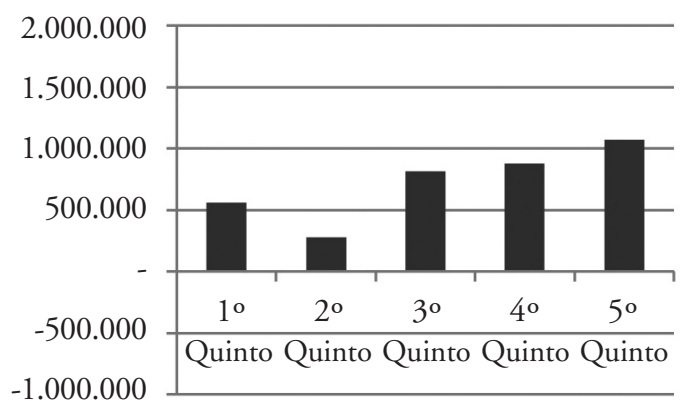

d) $2008 / 9$ a $2011 / 12 *$

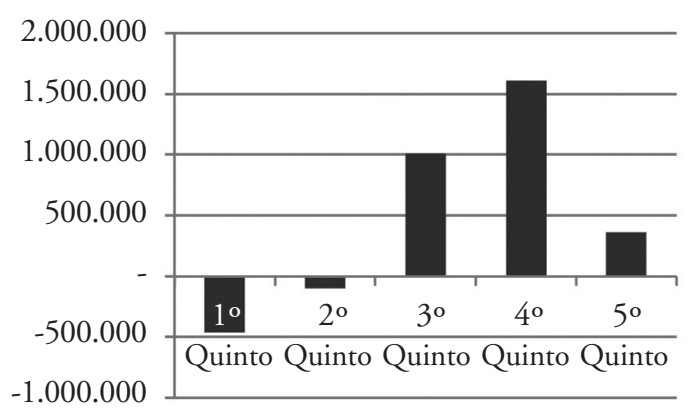

* Intervalo 2008/9-2011/12 é maior que os demais pois não houve PNAD em de 2010 (ano censitário).

Fonte: PNAD, 2002-2012 (elaboração dos autores). 
Os gráficos 2 exibem o saldo de empregos por quintos de qualidade do emprego de duas formas diferentes - uma delas segundo comparaçôes bienais. O gráfico 3 traz o saldo agregado do período, ou seja, entre 2002 e 2012.

De acordo com os quatro saldos bienais apresentados, a expansão dos postos de trabalho na década de 2000 se caracteriza predominantemente por um quadro de melhoria do emprego (segundo os modelos estilizados na Figura 1). No último período, o quadriênio de 2008-2012, observamos a criação de postos de trabalho concentrados nos quintos intermediários de qualidade do emprego simultânea à redução dos postos de pior qualidade. O saldo total do período, apresentado no gráfico 3 , mostra que o resultado final é fundamentalmente de melhoria do emprego (apesar de algumas características híbridas, que intercedem com outros modelos). Ou seja, a queda das desigualdades de rendimento se fez em um cenário que se aproxima da melhoria de emprego, principalmente entre os anos de 2004-2005 e 2008-2009. Esse fenômeno vai na contramão do que já ocorreu em momentos passados, no Brasil e em outros países, em que a melhoria de emprego geralmente era acompanhado de crescimento das desigualdades. Ainda que não seja possível contradizer as expectativas teóricas mais gerais sobre a relação entre padrōes de geração de emprego e movimento das desigualdades, nos- so caso sugere que a conexão entre os dois fenômenos não é tão mecânica. A relação seria direta $\mathrm{e}$ necessária se apenas o efeito de composição (ocupacional) importasse para a variação do patamar de desigualdade. Contudo, fatores extraocupacionais importam (composição de gênero, de idade, de escolaridade etc.) Além disso, mesmo que nos detivéssemos no aspecto ocupacional, conforme vimos pela expressão 1.3, há contribuiçôes associadas ao efeito de médias e de variância para entender como a estrutura ocupacional se relaciona com a desigualdade de renda diante dos diversos determinantes que esta tem.

As discussões em torno da expansão do emprego na década de 2000 frequentemente levantaram a suspeita de que a maior parte dos postos formais gerados na década se concentraria em empregos de qualidade relativamente baixa. $\mathrm{O}$ que observamos é exatamente o contrário disso: os novos empregos formais concentram-se principalmente nos dois últimos quintos, de maior renda, do ponto de vista relativo. Contudo, dada a imensa desigualdade que persiste (apesar de toda a queda dos indicadores, os patamares ainda são elevados), os primeiros quintos de ocupaçóes-setores concentram ocupaçóes cuja diferença substantiva de renda não é tão grande. Esse fato faz com que diagnósticos muito díspares possam ser traçados sobre essa mesma realidade. Do o ponto de vista do estoque de trabalhadores nas ocupaçōes,

Gráfico 3

Padrão de geração de emprego entre 2002 e 2012

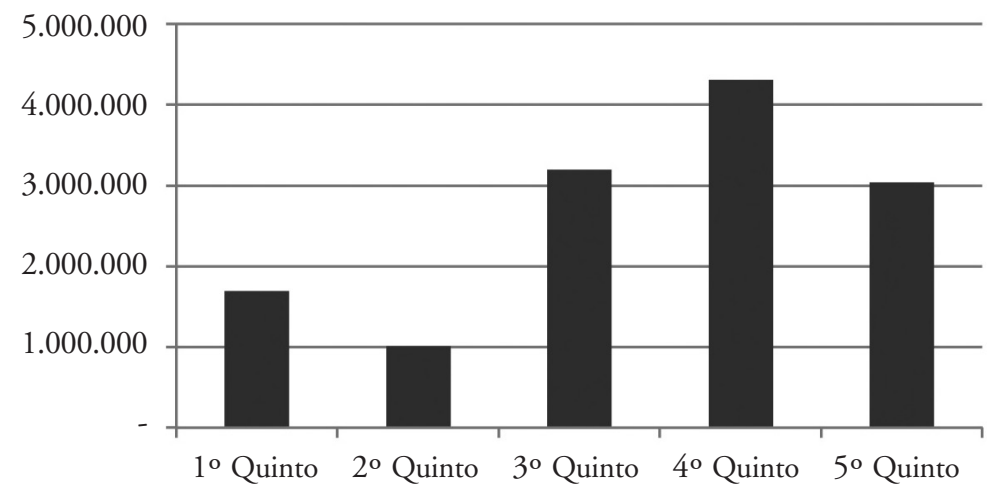

Fonte: PNAD, 2002-2012 (elaboração dos autores). 
o cenário ainda é de grande concentração de trabalhadores em ocupações cujo rendimento médio é inferior a dois salários mínimos. De um ponto de vista relacional (isto é, do fluxo/saldo entre os períodos), e levando em conta os processos de mudança, a expansão do emprego caracterizou-se por uma transferência da mão de obra para ocupaçóes relativamente mais bem remuneradas. De fato, o padrão dessa década é novidade frente aos das décadas anteriores, marcadas por profundas instabilidades no mercado de trabalho brasileiro (Cardoso, 1999; Guimarães, 2002). Essas mudanças qualitativas no emprego no Brasil durante a última década e sua relação com a desigualdade de renda nos levam, assim, a prosseguir a investigação para entender a relação dessa dinâmica com os processos associados à distribuição dos rendimentos no país nesse mesmo período.

\section{Decomposição do movimento da desigualdade de renda}

Como dissemos, a mera leitura visual e qualitativa dos gráficos apresentados não nos permite avaliar o movimento dos indicadores de desigualdade. Uma vez que os quintos mais elevados são também mais heterogêneos e desiguais em termos de distribuição de renda, um movimento de melhoria do emprego pode estar associado até ao aumento de desigualdades. Se há redução da desigualdade de renda, como é amplamente documentado na pesquisa empírica sobre o tema, podemos nos perguntar quais os pesos dos elementos, com um foco especial na dimensão ocupacional. Procedemos então à análise detida dos fatores de mudança da estrutura ocupacional sobre as desigualdades. A tabela 1 apresenta os resultados da decomposição do índice de desigualdade por ocupação, de acordo com as equações apresentadas na seção 4.1. ${ }^{10}$

Primeiramente apresentamos o estoque de desigualdade em cada período (decomposição derivada da fórmula 1.1a). No caso do modelo nulo, a decomposição é feita nas parcelas inter e intraocupacionais, sem variáveis de controle. No caso dos modelos com controles, há um componente adicional chamado de "nível individual", que se refere à variância explicada pelas demais variáveis independentes incluídas. ${ }^{11}$ A coluna do total mostra o valor bruto do logaritmo da renda para cada ano. Observamos que a queda é contínua, partindo de 1,041 , em 2002, e chegando a 0,802, em 2012. As colunas $\mathrm{R}^{2}$ apresentam a divisão dos componentes inter, intra e individual pela desigualdade total em cada ano, indicando a parcela de desigualdade devida a cada componente, numa escala de 0 a 1 .

O modelo nulo sugere que a maior parcela das desigualdades se deve às diferenças entre indivíduos dentro das ocupações, como pode ser visto pela avaliação numérica do componente na coluna intra, assim como sua importância relativa, que fica sempre ao redor de $60 \%$ ( $\mathrm{R}^{2}$ intra). Observamos também que uma queda ocorreu simultaneamente nos componentes entre e dentro das ocupaçôes, de forma que a parcela explicada por cada componente se mantêm praticamente invariável em termos relativos, como informam os valores da coluna $\mathrm{R}^{2}$. O modelo 2, com controles de raça, sexo, região e idade, aponta para uma conclusão aparentemente semelhante. A parcela das desigualdades explicada pelo componente ocupacional passa a ser menor (o $\mathrm{R}^{2}$ fica em torno de 0,34$)$, mas permanece relativamente estável ao longo do tempo, como no modelo anterior. Podemos ver a importância dos controles adicionados através de sua representatividade na explicação dos modelos comunicada na coluna $\mathrm{R}^{2}$, em torno de $25 \%$.

Por fim, no modelo 3 a variável de escolaridade é adicionada. Esses resultados alteram substancialmente as conclusões dos modelos anteriores. $\mathrm{O}$ tamanho do componente individual (sexo, raça, idade, região e escolaridade) se amplia de forma considerável. No período, sua importância explicativa oscila entre $55 \%$ para $47,1 \%$. As desigualdades internas às ocupaçôes, por sua vez, ocupam um patamar de 0,355 e sua importância relativa na variação da tendência é em média de $38 \%$. A sucessiva adição de controles mostra que parte considerável dos efeitos, que aparentemente seriam diferenças entre ocupaçôes, pode ser atribuída a fatores individuais inseridos no modelo 2 e principalmente à escolaridade, inserida no modelo 3. Ainda assim, as tendências associadas aos componentes inter e intraocupacionais se mostram significativas, uma vez que sua importância relativa na explicação da desigualdade de renda, somada, sempre ronda os $50 \%$. 
Tabela 1

Decomposição da variância do logaritmo da renda

\begin{tabular}{|c|c|c|c|c|c|c|c|c|c|c|}
\hline \multicolumn{11}{|c|}{ Modelo 1 (apenas ocupaçóes) } \\
\hline \multirow[b]{2}{*}{ Ano } & \multicolumn{4}{|c|}{ Estoque de desigualdade } & \multicolumn{3}{|c|}{ Decomposição dinâmica } & \multicolumn{3}{|l|}{$\mathbf{R}^{2}$} \\
\hline & $\begin{array}{l}\text { Inter } \\
V_{\text {inter }}\end{array}$ & $\begin{array}{l}\text { Intra } \\
V_{\text {intra }}\end{array}$ & $\begin{array}{l}\text { Nível } \\
\text { individual } \\
V_{\text {individual }}\end{array}$ & $\begin{array}{l}\text { Total } \\
V_{\text {total }}\end{array}$ & $\begin{array}{l}\text { Efeito } \\
\text { composição } \\
\Delta_{C}\end{array}$ & $\begin{array}{l}\text { Efeito } \\
\text { média } \\
\Delta_{M}\end{array}$ & $\begin{array}{l}\text { Efeito } \\
\text { variância } \\
\Delta_{V}\end{array}$ & Inter & Intra & $\begin{array}{l}\text { Nível } \\
\text { individual }\end{array}$ \\
\hline 2002 & 0,446 & 0,595 & - & 1,041 & 0,000 & 0,000 & 0,000 & 0,429 & 0,571 & - \\
\hline 2003 & 0,433 & 0,604 & - & 1,036 & $-0,001$ & $-0,011$ & 0,007 & 0,417 & 0,583 & - \\
\hline 2004 & 0,412 & 0,585 & - & 0,997 & $-0,006$ & $-0,026$ & $-0,011$ & 0,413 & 0,587 & - \\
\hline 2005 & 0,416 & 0,573 & - & 0,989 & $-0,004$ & $-0,025$ & $-0,022$ & 0,421 & 0,579 & - \\
\hline 2006 & 0,411 & 0,563 & - & 0,973 & $-0,010$ & $-0,029$ & $-0,028$ & 0,422 & 0,578 & - \\
\hline 2007 & 0,368 & 0,556 & - & 0,924 & $-0,033$ & $-0,060$ & $-0,025$ & 0,398 & 0,602 & - \\
\hline 2008 & 0,378 & 0,532 & - & 0,910 & $-0,042$ & $-0,043$ & $-0,046$ & 0,415 & 0,585 & - \\
\hline 2009 & 0,373 & 0,515 & - & 0,888 & $-0,038$ & $-0,058$ & $-0,057$ & 0,420 & 0,580 & - \\
\hline 2011 & 0,322 & 0,489 & - & 0,812 & $-0,071$ & $-0,082$ & $-0,076$ & 0,397 & 0,603 & - \\
\hline 2012 & 0,307 & 0,495 & - & 0,802 & $-0,076$ & $-0,105$ & $-0,058$ & 0,383 & 0,617 & - \\
\hline
\end{tabular}

Modelo 2 (ocupaçóes com controle de raça, sexo, idade e regióes)

\begin{tabular}{|c|c|c|c|c|c|c|c|c|c|c|}
\hline \multirow[b]{2}{*}{ Ano } & \multicolumn{4}{|c|}{ Estoque de desigualdade } & \multicolumn{3}{|c|}{ Decomposição dinâmica } & \multicolumn{3}{|l|}{$\mathbf{R}^{2}$} \\
\hline & $\begin{array}{l}\text { Inter } \\
V_{\text {inter }}\end{array}$ & $\begin{array}{l}\text { Intra } \\
V_{\text {intra }}\end{array}$ & $\begin{array}{l}\text { Nível } \\
\text { individual } \\
V_{\text {individual }}\end{array}$ & $\begin{array}{l}\text { Total } \\
V_{\text {total }}\end{array}$ & $\begin{array}{l}\text { Efeito } \\
\text { composição } \\
\Delta_{C}\end{array}$ & $\begin{array}{l}\text { Efeito } \\
\text { média } \\
\Delta_{M}\end{array}$ & $\begin{array}{l}\text { Efeito } \\
\text { variância } \\
\Delta_{V}\end{array}$ & Inter & Intra & $\begin{array}{l}\text { Nível } \\
\text { individual }\end{array}$ \\
\hline 2002 & 0,360 & 0,407 & 0,273 & 1,041 & 0,000 & 0,000 & 0,000 & 0,346 & 0,391 & 0,263 \\
\hline 2003 & 0,343 & 0,450 & 0,243 & 1,036 & 0,000 & $-0,016$ & 0,042 & 0,331 & 0,434 & 0,234 \\
\hline 2004 & 0,330 & 0,419 & 0,248 & 0,997 & $-0,005$ & $-0,024$ & 0,010 & 0,331 & 0,420 & 0,249 \\
\hline 2005 & 0,336 & 0,423 & 0,230 & 0,989 & $-0,003$ & $-0,020$ & 0,015 & 0,340 & 0,427 & 0,232 \\
\hline 2006 & 0,335 & 0,393 & 0,245 & 0,973 & $-0,006$ & $-0,021$ & $-0,012$ & 0,344 & 0,404 & 0,252 \\
\hline 2007 & 0,299 & 0,358 & 0,267 & 0,924 & $-0,023$ & $-0,047$ & $-0,040$ & 0,324 & 0,387 & 0,289 \\
\hline 2008 & 0,310 & 0,383 & 0,217 & 0,910 & $-0,028$ & $-0,033$ & $-0,013$ & 0,341 & 0,421 & 0,238 \\
\hline 2009 & 0,309 & 0,363 & 0,216 & 0,888 & $-0,026$ & $-0,040$ & $-0,029$ & 0,348 & 0,409 & 0,243 \\
\hline 2011 & 0,271 & 0,331 & 0,210 & 0,812 & $-0,051$ & $-0,059$ & $-0,055$ & 0,334 & 0,408 & 0,258 \\
\hline 2012 & 0,257 & 0,313 & 0,233 & 0,802 & $-0,055$ & $-0,077$ & $-0,066$ & 0,320 & 0,390 & 0,290 \\
\hline
\end{tabular}

Modelo 3 (ocupaçóes com controle de raça, sexo, idade, regióes e educação)

Estoque de desigualdade

\begin{tabular}{|c|c|c|c|c|c|c|c|c|c|c|}
\hline Ano & $\begin{array}{l}\text { Inter } \\
V_{\text {inter }}\end{array}$ & $\begin{array}{l}\text { Intra } \\
V_{\text {intra }}\end{array}$ & $\begin{array}{l}\text { Nível } \\
\text { individual } \\
V_{\text {individual }}\end{array}$ & $\begin{array}{l}\text { Total } \\
V_{\text {total }}\end{array}$ & $\begin{array}{l}\text { Efeito } \\
\text { composição } \\
\Delta_{C}\end{array}$ & $\begin{array}{l}\text { Efeito } \\
\text { média } \\
\Delta_{M}\end{array}$ & $\begin{array}{l}\text { Efeito } \\
\text { variância } \\
\Delta_{V}\end{array}$ & Inter & Intra & $\begin{array}{l}\text { Nível } \\
\text { individual }\end{array}$ \\
\hline 2002 & 0,142 & 0,326 & 0,573 & 1,041 & 0,000 & 0,000 & 0,000 & 0,137 & 0,313 & 0,550 \\
\hline 2003 & 0,138 & 0,394 & 0,505 & 1,036 & $-0,001$ & $-0,003$ & 0,067 & 0,133 & 0,380 & 0,487 \\
\hline 2004 & 0,133 & 0,352 & 0,512 & 0,997 & $-0,002$ & $-0,006$ & 0,025 & 0,134 & 0,353 & 0,514 \\
\hline 2005 & 0,142 & 0,385 & 0,461 & 0,989 & $-0,003$ & 0,002 & 0,060 & 0,144 & 0,389 & 0,467 \\
\hline 2006 & 0,141 & 0,352 & 0,480 & 0,973 & $-0,007$ & 0,003 & 0,030 & 0,145 & 0,362 & 0,493 \\
\hline 2007 & 0,127 & 0,377 & 0,419 & 0,924 & $-0,020$ & $-0,005$ & 0,062 & 0,138 & 0,409 & 0,454 \\
\hline 2008 & 0,149 & 0,384 & 0,377 & 0,910 & $-0,025$ & 0,019 & 0,071 & 0,163 & 0,422 & 0,415 \\
\hline 2009 & 0,152 & 0,359 & 0,377 & 0,888 & $-0,027$ & 0,021 & 0,048 & 0,171 & 0,404 & 0,425 \\
\hline 2011 & 0,133 & 0,316 & 0,363 & 0,812 & $-0,046$ & 0,015 & 0,012 & 0,164 & 0,389 & 0,447 \\
\hline 2012 & 0,123 & 0,301 & 0,378 & 0,802 & $-0,052$ & 0,002 & 0,006 & 0,153 & 0,376 & 0,471 \\
\hline
\end{tabular}

Fonte: PNAD, 2002-2012 (elaboração dos autores). 
Tabela 2

Resumo: contribuição de cada componente para a queda das desigualdades de rendimento (2002-2012)

Variação percentual dos componentes estáticos (2002-2012)

\begin{tabular}{llll}
\hline & $\begin{array}{l}\text { Modelo 1 } \\
\text { (sem controles })\end{array}$ & $\begin{array}{l}\text { Modelo 2 } \\
(+ \text { sexo, raça, idade, regiōes })\end{array}$ & $\begin{array}{l}\text { Modelo 3 } \\
\text { + sexo, raça, idade, regiōes, } \\
\text { escolaridade })\end{array}$ \\
\hline$\Delta$ inter & $-58,16 \%(-0,14)$ & $-43,46 \%(-0,10)$ & $-7,95 \%(-0,01)$ \\
\hline$\Delta$ intra & $-41,84 \%(-0,10)$ & $-39,66 \%(-0,09)$ & $-10,46 \%(-0,02)$ \\
\hline$\Delta$ variáveis & & $-16,88 \%(-0,04)$ & $-81,59 \%(-0,19)$ \\
\hline Total & $-100,00 \%(-0,24)$ & $-100,00 \%(-0,24)$ & $-100,00 \%(-0,24)$ \\
\hline
\end{tabular}

Saldos da decomposição dinâmica - componentes ocupacionais

\begin{tabular}{llll}
\hline Efeito de composição $\left(\Delta_{C}\right)$ & $-31,80 \%(-0,07)$ & $-23,00 \%(-0,05)$ & $-21,80 \%(-0,05)$ \\
\hline Efeito de médias $\left(\Delta_{M}\right)$ & $-43,90 \%(-0,10)$ & $-32,20 \%(-0,07)$ & $0,80 \%(0,002)$ \\
\hline Efeito de variância $\left(\Delta_{V}\right)$ & $-24,30 \%(-0,05)$ & $-27,60 \%(-0,06)$ & $2,50 \%(0,006)$ \\
\hline Total & $-100,00 \%(-0,24)$ & $-82,80 \%(-0,19)$ & $-18,40 \%(-0,044)$ \\
\hline
\end{tabular}

Fonte: PNAD, 2002-2012 (elaboração dos autores).

Ainda de acordo com os resultados do modelo 3, é possível ter uma ideia mais precisa sobre os componentes que influenciaram os movimentos das tendências ocupacionais. Em 2002, quando a desigualdade total medida pela variância do logaritmo da renda era 1,041, os componentes ocupacionais $V_{\text {inter e }} V_{\text {intra }}$ eram responsáveis por 0,468 desse índice $(0,142+0,326)$. Ao fim do período, em 2012, esse valor caiu para 0,424 - e a diferença é exatamente aquela captada pela soma dos três efeitos identificados pela decomposição empregada: 0,424 $=0,468+(-0,052+0,002+0,006)-$ conforme a expressão 1.3. Isso indica, portanto, que os componentes ocupacionais tiveram um pequeno ou moderado papel na queda das desigualdades: foram responsáveis por um decréscimo de 0,044 em nosso índice, e essa queda se deveu predominantemente à mudanças na composição das ocupaçôes, como mostra a última linha da tabela 1 e a álgebra demonstrada.

A queda total da desigualdade de renda medida pelo logaritmo foi de 0,239 , como informa a simples subtração do último ponto da tendência em relação ao primeiro. Com outras manipulações algébricas igualmente simples, feitas nos diferentes modelos, chegamos à tabela 2, que representa a importância relativa dos componentes estudados e enfoca apenas a queda da desigualdade. Assim, ela apresenta o peso relativo de cada componente na construção do movimento de queda. Torna-se bastante clara a redução de importância dos componentes ocupacionais para a análise da queda da desigualdade à medida que adicionamos novas variáveis aos modelos. É interessante comparar as mudanças entre os modelos 2 e 3 . Vemos que a importância explicativa do componente interocupacional cai de $43 \%$ para $7 \%,{ }^{12}$ enquanto o intraocupacional cai de $39 \%$ para $10, \%$. A importância relativa das variáveis de nível individual, por sua vez, cresce de $17 \%$ para $81 \%$. Como a única variável adicionada nesse passo se refere ao nível de escolaridade, é possível atribuir as mudanças à adição desse controle. Ou seja, no que diz respeito à análise da queda da desigualdade, chegamos a resultados similares ao de outros pesquisadores que haviam estudado o tema.

No entanto, sublinhamos que as mudanças na estrutura ocupacional não são triviais. Aproxima- 
damente $18 \%$ da queda da desigualdade do rendimento do trabalho, segundo nossos modelos, se deveram a mudanças ocupacionais. Nossa estratégia de decomposição mostra que o fator determinante foi o efeito de composição, cuja importância explicativa praticamente não é afetada pela adição do controle de educação, enquanto os componentes de média e variância têm seus efeitos reduzidos para quase zero. Portanto, a desigualdade entre ocupações caiu porque reduziu-se a proporção (o tamanho) de ocupações nos extremos da distribuição de renda e/ou porque houve redução da proporção ocupada por ocupaçōes internamente muito desiguais no mercado de trabalho.

Em síntese, nossos resultados podem ser interpretados em dois sentidos distintos, uma vez que apresentam dados do ponto de vista estático (anual) e dinâmico (mudança da desigualdade e dos fatores associados a ela). A tabela 1 fornece mais informaçôes para pensar a do ponto de vista estático. Como mencionamos, a coluna $\mathrm{R}^{2}$ traz a importância do componente ocupacional a cada ano. Observando os resultados do modelo 3 , que já inclui todos os controles, notamos que os componentes ocupacionais tem uma importância elevada na explicação da desigualdade em cada um dos anos. Em 2012, apenas a desigualdade entre ocupaçōes já explica cerca de $15,3 \%$ da desigualdade do rendimento do trabalho. A desigualdade entre indivíduos dentro das ocupações (que, de certa forma, também é uma característica estrutural das ocupações) é responsável por $37,6 \%$ da variância nesse mesmo ano. Ao longo do período considerado, somados, os componentes inter e intraocupacionais são responsáveis por cerca de $50 \%$ da variância do logaritmo da renda. Isso demonstra de forma significativa como a estrutura ocupacional é um traço fundamental da desigualdade de rendimentos no Brasil, tanto na dimensão que diferencia as ocupações entre si como em sua composição interna e na dispersão salarial que nelas está presente.

Do ponto de vista da dinâmica da desigualdade de renda do trabalho, que coloca em foco direto a queda da desigualdade em si, como a maior parte dessa queda se deve às nossas variáveis de controle (em especial, a escolaridade), a importância relativa dos componentes ocupacionais foi lentamente crescendo ao longo dos anos. A soma do $\mathrm{R}^{2}$ dos componentes inter e intra se eleva pouco a pouco. Como essa medida é relativa, essa elevação se deve não ao crescimento absoluto dos termos, mas à diminuição de importância de outros fatores, como o educacional, para a tendência avaliada. Desse modo, ainda que a estrutura ocupacional tenha tido um papel coadjuvante na queda (fluxo) da desigualdade de renda do trabalho - apenas pelo efeito de composição -, isso fez com que se ampliasse o seu papel explicativo no estoque.

Nossos resultados são assertivos sobre um ponto muito importante: os recentes ganhos salariais dos trabalhadores e a queda da desigualdade não estão relacionados a mudanças na hierarquia e em aspectos da estrutura ocupacional. Houve homogeneização da distribuição e dos retornos da educação, além de diminuição de disparidades associadas a outros aspectos importantes, como gênero. No entanto, as distâncias salariais entre ocupações, bem como os mecanismos de premiação desigual dos indivíduos dentro das ocupaçôes, se mantiveram estáveis - observação que é possível apenas se houver controle por um conjunto de variáveis. $\mathrm{Ou}$ seja, as significativas mudanças ocorridas no mercado de trabalho na última década não afetaram um eixo fundamental, que contribui na organização do processo de estratificação. Esses resultados apontam para a natureza estrutural da dimensão ocupacional e de sua resiliência a mudanças. A estrutura ocupacional muda de forma mais lenta e depende de movimentos de mais de uma geração.

\section{Discussōes e considerações finais}

Ao longo deste artigo, com duas estratégias distintas e complementares, investigamos a relação entre geração de emprego, estrutura ocupacional e desigualdade de renda no Brasil. Mostramos que o padrão de expansão do emprego na última década implicou, de modo geral, uma melhoria relativa dos postos de trabalho: as ocupaçóes criadas se concentram nos quintos mais altos de renda (melhoria de emprego). A literatura econômica principalmente por meio da hipótese de skill biased technological change, tanto em sua versão original 
quanto na de Autor, Levy e Murnane (2003) - indica que esse quadro pode estar ligado ao aumento da desigualdade observado em uma séria de países desenvolvidos, uma vez que reflete o aquecimento da demanda por mais altas qualificações (e, por conseguinte, a elevação dos prêmios salariais). Nossos resultados mostram que, no Brasil, esse tipo de tendência não se aplica: experimentamos queda em todos os índices que mensuram a desigualdade de rendimentos ao mesmo tempo que vivenciávamos significativas mudanças no mercado de trabalho, um job upgrading.

A geração de empregos transferiu os trabalhadores para ocupaçōes e setores em que se remunera mais, e simultaneamente houve redução do tamanho das ocupações de mais baixo nível salarial. Como vimos, a redistribuição dos postos de trabalho (captada pelo efeito de composição) é responsável por cerca de $20 \%$ da queda das desigualdades (tabela 2). Nesse sentido, houve melhoria do emprego com equidade. Esse é um processo bastante distinto de uma mudança no mercado de trabalho que pudesse ter sido provocada pela demanda generalizada de trabalhadores altamente qualificados e escolarizados. Por isso, melhoria ocupacional não precisa estar necessariamente ligada aos mesmos diagnósticos geralmente mobilizados pelo debate econômico.

Nossos modelos de decomposição da desigualdade de rendimentos (variância do logaritmo da renda) evidenciaram a importância empírica de um tipo de dimensão pouco mobilizada na literatura sobre a desigualdade de renda no Brasil: a estrutura ocupacional. Para explicar o estoque da tendência, mesmo com rigorosos controles estatísticos, a desigualdade é substancialmente relacionada às ocupações, tanto a diferenças entre estas como à sua dispersão interna. Também mostramos que, ainda que o fator determinante para a queda da desigualdade tenha sido predominantemente educacional, mudanças relacionadas ao tamanho das ocupações tiveram efeitos não trivais sobre a queda da desigualdade de renda do trabalho no período.

Dada a queda dos componentes de nível individual, hoje, o componente interocupacional responde por uma parcela relevante do estoque de desigualdades - a $15 \%$, enquanto o intraocupacional, a 37,6\%, em 2012. As desigualdades dentro (intra) das ocu- pações são fruto de uma interseção de uma série de elementos, desde a heterogeneidade entre habilidades e características individuais até mecanismos muito diferentes de competição, acesso e valorização das qualificações e do desempenho. No entanto, a abertura à heterogeneidade é em si uma característica institucional das ocupações. As diferenças nos patamares de desigualdade dentro de um emprego público e de um emprego privado não são aleatórias, mas sistematicamente ligadas às normas formais e informais que regem o acesso e as rotinas ocupacionais. Desse modo, dizemos que também a desigualdade entre indivíduos dentro das ocupações é um aspecto estrutural do sistema ocupacional. Somados, os dois componentes concorrem cada vez mais com a importância explicativa em comparação a outros quesitos, como raça, sexo, idade, região e escolaridade. Isso não significa que estes tenham atualmente tamanho diminuto ou que deixaram de ser importantes, mas indica a relevância crescente da dimensão ocupacional para a compreensão de como se comporta a desigualdade de renda no Brasil.

Os patamares de desigualdade no país, apesar de inferiores aos padrôes antes verificados, ainda são muito altos se tomamos como referência o plano internacional. As evidências apresentamos, além de terem interesse científico, são importantes também do ponto de vista da política social. Em resumo, o mercado de trabalho brasileiro mudou e se tornou menos desigual, mas isso se deve fundamentalmente à dinâmica da redução das barreiras de oportunidades educacionais, à escolarização dos trabalhadores e à redução dos retornos salariais pela educação. $\mathrm{O}$ componente sociológico ligado à divisão do trabalho e às hierarquias de status entre ocupaçôes permaneneu praticamente inalterado.

Tendo esses resultados em perspectiva, emergem perguntas interessantes, que apontam para o entendimento da dinâmica ocupacional e educacional em interação. Como as credenciais educacionais não são utilizadas em um vácuo no mercado de trabalho, pesquisas posteriores podem responder, em termos parecidos com os que apresentamos aqui, quais seriam as credenciais educacionais que tiveram mudanças mais significativas para a desigualdade de renda e em quais setores do mercado de trabalho o fenômeno ocorreu de forma mais in- 
tensa. O ganho analítico da compreensão de suas fontes estruturais é significativo e merece ser mais bem explorado por quem se dedica ao estudo do fenômeno. Mais especificamente, esperamos que nossa pesquisa seja útil ao mostrar a importância da estrutura ocupacional para entender os padróes de desigualdade de renda no Brasil. Acreditamos ter evidenciado, com nossos resultados, a relevância analítica e metodológica de uma orientação sociológica. Ainda assim, estivemos atentos à rica literatura econômica sobre o tema no Brasil, e acreditamos que nosso trabalho seja um sinal da complementaridade dessas abordagens. Esta é apenas uma aproximação inicial ao tema, que merece ser estudado num escopo de tempo mais amplo e sob o viés da interação dessa dimensão temporal com os padrões de mudança demográfica. Que as novas pesquisas levem em conta perspectivas interdisciplinares e contribuam, em diálogo, para um conhecimento cumulativo e relevante.

\section{Notas}

1 Os sistemas de classificação ocupacional e setorial em geral possuem muitas categorias: entre trezentas e quinhentas de ocupações e entre cem e duzentas de setores. Obviamente, nem todas as células dessa grande matriz de ocupações/setor serão preenchidas - ainda mais em pesquisas amostrais. Para minimizar o problema de lacunas, os autores fundiram dados de vários anos e fizeram agregações e desagregações das categorias ocupacionais e setoriais. Consequentemente, as inferências traçadas se referem à média do período coberto.

2 Apesar da variância do logaritmo da renda não ser um dos melhores indicadores de desigualdade, observamos que suas medições seguem de perto as tendências e inflexões dos índices de Gini e de Theil. A crítica à essa medida apoia-se principalmente no fato de que as transformações não lineares da renda levam à violação do princípio da transferência (Cowell, 1977). No entanto, esta é a única medida de desigualdade que permite a decomposição multivariada por meio de modelos de regressão, abrindo caminho para análises detalhadas e sofisticadas.

3 Não é preciso fazer suposições sobre o formato da distribuição dos resíduos em amostras grandes. Apenas assinalamos que são independentes, têm média zero e variância heterocedástica (em função da ocupação e do tempo).

4 O grupo dos brancos inclui também os amarelos. Os não brancos são os pretos, pardos, indígenas e outros.

5 Importante lembrar que nas equaçôes 1.2 e 1.3 $r_{j t}^{2}=\left(\mu_{j t}-\overline{\mu_{t}}\right)^{2}$.

$6 \mathrm{Na}$ população, a variância condicional dos erros é $E\left[e_{i j}^{2} \mid\right.$ ocup $\left._{i j}, x_{i k}\right]$, uma função das ocupações e das demais variáveis explicativas. A regressão dos resíduos ao quadrado é um estimador desse valor. Assumir linearidade na regressão da função amostral da variância não é um pressuposto forte, uma vez que todas as variáveis são categóricas e utilizadas como dummies. Num modelo como esse (apesar de não ser saturado), a relação linear é uma boa aproximação para a esperança condicional.

7 Wright e Dwyer (2003) argumentam que a mediana é uma medida mais robusta da tendência central e menos influenciada por observações extremas. Isso é verdade, porém, a mediana é também uma medida mais ineficiente, pois tem maior erro padrão e, por isso, é menos precisa. Como o número de caso nas ocupações-setor pode não ser muito grande, optamos pela média porque sua precisão cresce mais rapidamente em amostras finitas, quando elevamos o número de casos.

8 A definição de uma ocupação-setor é dada pela seguinte fórmula: ocupação-setor $=$ ocupação + (setor $\times$ 10000). Criamos assim um número identificador do cruzamento entre ocupações e setores sem que efetivamente tenhamos que gerar uma grande matriz, que seria intratável analiticamente.

9 Os resíduos ao quadrado seguem aproximadamente uma distribuição qui-quadrado, que é assimétrica à direita e truncada no valor zero. A regressão por mínimos quadrados (MQO) não impede que obtenhamos valores preditos negativos (que não fariam sentido, uma vez que estamos estimando a variância). Um modelo alternativo (e mais adequando em alguns casos) seria o uso de uma regressão Gama, ajustada por máxima verossimilhança. Contudo, não obtivemos valores preditos fora do escopo de possibilidades - e as estimativas da MQO se aproximam muito daquelas obtidas pela Gama, com a vantagem de serem mais eficientes e computacionalmente menos intensivos.

10 Apresentamos apenas os resultados da decomposição. A apresentação dos coeficientes de regressão é irrelevante para os nossos propósitos. No entanto, como sublinhamos na seção anterior, o material para a replicação completa pode nos ser requisitado a qualquer momento. 
11 Quando aplicamos os modelos de regressão das fórmulas 2.1 e 2.3 e então utilizamos seus valores estimados na fórmula 3.1 (que substitui a 1.1a), a soma dos componentes inter e intra passa a ser menor que a desigualdade total no período. Isso ocorre porque parcela da desigualdade foi explicada pelas demais variáveis de controle. Podemos estimar a contribuição dessas variáveis para o estoque total de desigualdades fazendo uma simples subtração: $V_{\text {individual }}=V_{\text {total }}-\left(V_{\text {inter }}+V_{\text {intra }}\right)$, onde $\mathrm{V}_{\text {individual }}$ é justamente a parcela explicada pelas variáveis de controle. O subscrito "individual" apenas indica que são características dos indivíduos (raça sexo, idade, escolaridade), não das ocupações.

12 Esse valor se refere à parcela da queda das desigualdades que é devida ao componente. Seu calculo é dado pela divisão da variação com componente entre 2002 e 2012 e pela variacão total das desigualdades no mesmo período: $\frac{\left(V_{\text {itra }}^{2012}-V_{\text {intra }}^{2002}\right)}{\left(V_{\text {total }}^{2012}-V_{\text {total }}^{202}\right)}$. Assim, utilizando os dados da tabela 1 para o modelo 3, temos: $\frac{(0,123-0,142)}{(0,802-1,041)}=0,0795=7,59 \%$.

\section{BIBLIOGRAFIA}

AUTOR, David H.; KATZ, Lawrance F. \& KEARNEY, Melissa S. (2006), "The polarization of the US labor market". American Economic Review, 96: 189-194.

AUTOR, David H.; LEVY, Frank \& MURNANE, R. (2003), "The skill content of recent technological change: an empirical exploration". Quartely Journal of Economics, 118 (4): 12791334.

BARROS, Ricardo Paes de; CARVALHO, Mirela de; FRANCO, Samuel \& MENDONÇA, Rosane. (2006a), "Determinantes imediatos da queda da desigualdade de renda brasileira", in R. P. Barros, M. N. Foguel et al. (orgs.), Desigualdade de renda no Brasil: uma análise da queda recente, Brasília, Ipea.

(2006B), "A queda recente da desigualdade de renda no Brasil", in R. P. Barros, M. N. Foguel et al. (orgs.), Desigualdade de renda no Brasil: uma análise da queda recente, Brasília, Ipea. BARROS, Ricardo Paes de; FRANCO, Samuel \& MENDONÇA, Rosane. (2006), "A recente queda na desigualdade de renda e o acelera- do progresso educacional brasileiro da última década", in R. P. Barros, M. N. Foguel et al. (orgs.), Desigualdade de renda no Brasil: uma análise da queda recente, Brasília, Ipea.

BECKER, Gary S. (1976), The economic approach to human behavior. Chicago, University of Chicago Press.

BLAU, Peter Michael \& DUNCAN, Otis Dudley. (1967), The American occupational structure. New York, Wiley.

BREEN, Richard \&ROTTMAN, David B. (1995), Class stratification: a comparative perspective. New York, Harvester Wheatsheaf.

CARDOSO, Adalberto Moreira. (1999), Sindicatos, trabalhadores e a coqueluche neoliberal: a Era Vargas acabou? Rio de Janeiro, Editora FGV.

COWELL, Frank A. (1977), Measuring inequality. Oxford, Philip Allan.

DIPRETE, Thomas; GOUX, Dominique; MAURIN, Eric \& QUESNEL-VALLEE, Amelie. (2006), "Work and pay in flexible and regulated labor markets: A generalized perspective on institutional evolution and inequality trends in Europe and the US.”. Research in Social Stratification and Mobility, 24 (3): 311-332.

FERNANDEZ-MACÍAS, E. (2012), "Job polarization in Europe? Changes in the employment structure and job quality, 1995-2007". Work and Occupations, 39 (2): 157-182.

FERREIRA, Francisco H. G.; BARROS, Ricardo Paes de. (1998), "Climbing a moving mountain: explaining the decline in income inequality in Brazil from 1976 to 1996". I Workshop da LACEA/IDB/World Bank Inequality and Poverty Network, Buenos Aires.

FERREIRA, Francisco H. G.; LEITE, Philippe G.; LITCHFIELD, Julie \& ULYSSEA, Gabriel. (2006), "Ascensão e queda da desigualdade de renda no Brasil". Econômica, 8 (1): 147-169.

FERREIRA, Francisco H. G. \& LITCHFIELD, Julie. (2001), "Education or inflation? The Micro and Macroeconomics of the Brazilian Income Distribution during 1981-1995”. Cuadernos de Economía, 38 (114): 209-238.

GOLDIN, C. \& KATZ, L. (2008), The race between education and technology. Cambridge, MA, Harvard University Press. 
GOLDTHORPE, John H. (2000), On sociology: numbers, narratives, and the integration of research and theory. Oxford/Nova York, Oxford University Press.

. (2007), On sociology - Illustration and Retrospect. 2 ed. Stanford, Stanford University Press. GOOS, Maarten \& MANNING, Alan. (2007), "Lousy and lovely jobs: the rising polarization of work in Britain". Review of Economics and Statistics, 89 (1): 118-133.

GOOS, Maarten; MANNING, Alan \& SALOMONS, Ana. (2009), "Job polarization in Europe”. American Economic Review, 99 (2): 58-63.

GRUSKY, David B. \& GALESCU, Gabriela. (2005), "Foundations of a neo-durkheimmian class analysis", in E. O. Wright (org.), Approaches to class analysis, Cambridge, Cambridge University Press.

GRUSKY, David B. \& SORENSEN, Jesper B. (1998), "Can class analysis be salvaged?". The American Journal of Sociology, 103 (5): 1187-1234.

GRUSKY, David B. \& WEEDEN, Kim. (2008), "Are There Social Classes? A Framework for Testing Sociology's Favorite Concept", in A. Lareau e D. Conley (orgs.), Social class: how does it work?, Nova York, Russel Sage Foundation.

GUIMARÃES, Nadya Araujo. (2002), "Por uma sociologia do desemprego: contextos societais, construçóes normativas e experiências subjetivas". Revista Brasileira de Ciências Sociais, 17 (50): 103-122.

KALLEBERG, Arne. (2012), "Job quality and precarious work: clarifications, controversies and challenges". Work and Occupations, 39: 427-448.

KIM, Changwan \& SAKAMOTO, Arthur. (2008), "The rise of intra-occupational wage inequality in the United States, 1983 to 2002". American Sociological Review, 73: 129-157.

KNIGHT, J. \& SALBOT, R. (1983), "Education expantion and the Kuznets effect". American Economic Review, 73: 1132-1136.

LANGONI, Carlos Geraldo. (2005), Distribuição de renda e desenvolvimento econômico do Brasil. 3 ed. Rio de Janeiro, Editora FGV.

LEMIEUX, T. (2006), "Increasing residual wage inequality: composition effects, noisy data, or rising demand for skill?". American Economic Review, 96 (3): 461-498.

(2008), "The changing nature or wage inequality". Journal of Population Economics, 21: 21-48.

LIU, Yujia \& GRUSKY, David B. (2013), “The payoff to skill in the third industrial revolution”. American Journal of Sociology, 118 (5): 1330-1374.

MANNING, Alan. (2003), "The real thin theory: monopsony in modern labour markets". Labour Economics, 10 (2): 105-131.

MINCER, Jacob. (1974), Schooling, experience and earnings. Nova York, NBER/Columbia University Press.

MORRIS, Martina \& WESTERN, Bruce. (1999), "Inequality in Earnings at the Close of the Twentieth Century". Annual Review of Sociology, 25: 623-657.

MOUW, Ted \& KALLEBERG, Arne. (2010), "Occupations and the structure of wage inequality in the United States, 19080s to 2000s". American Sociological Review, 75 (3): 402-431.

NEVES, Jorge A. (2005), "Labor force classes and the earnings determination of the farm population in Brazil: 1973, 1982 and 1988". Research in Social Stratification and Mobility, 22: 423-475.

OESCH, D. \& MENES, R. (2012), "Upgrading or polarization? Occupational change in Britain, Germany, Spain and Switzerland, 19902008". Socio-Economic Review, 9: 503-532.

POCHMAN, Márcio. (2006), "Mercado de trabalho no Brasil: o que há de novo?”. Parcerias Estratégicas, 22 jun.

SANTOS, José Alcides Figueiredo. (2002), Estrutura de posiçôes de classe no Brasil: mapeamento, mudanças e efeitos na renda. Belo Horizonte, Editora UFMG.

SILVA, Nelson do Valle. (2003), "Os rendimentos pessoais”, in C. Hasenbalg e N. V. Silva (orgs.), Origens e destinos: desigualdades sociais ao longo da vida, Rio de Janeiro, Topbooks.

SORENSEN, Aage. (1996), "The structural basis of social inequality". The American Journal of Sociology, 101 (5): 1333-1365.

SORENSEN, Aage \& KALLEBERG, Arne L. (1979), An outline of a theory of the matching 
of persons to jobs. Madison, WI, University of Wisconsin (mimeo).

TAVARES, Priscilla Albuquerque \& MENEZES-FILHO, Naercio Aquino. (2011), "Human capital and the recent decline of earnings inequality in Brazil". Brazilian Review of Econometrics, 31 (2): 231-257.

WEEDEN, Kim A. (2002), "Why do some occupations pay more than others? Social closures and earnings inequality in the United States". American Journal of Sociology, 108: 55-101.

WEEDEN, Kim; KIM, Young-Mi; CARLO, Matthew Di \& GRUSKY, David B. (2007), "Social class and earnings inequality". American Behavioral Scientist, 50 (5): 702-736.

WESTERN, Bruce \& BLOOME, Deirdre. (2009), "Variance function regressions for studying inequality”. Sociological Methodology, 39: 293-326.

WILLIAMS, Mark. (2010), "The changing structure of occupations and wage inequality in Great Britain, 1970-1990s”. Encontro do ISA Research Comitee on Social Stratification (RC28), Haifa.

WRIGHT, Erik Olin. (1997), Class counts: comparative studies in class analysis. Cambridge, Cambridge University Press.

WRIGHT, Erik Olin \& DWYER, Rachel E. (2003), "The patterns of job expansions in the USA: a comparison of the 1960s and 1990s". Socio-Economic Review, 1: 289-325. 


\section{OS IMPACTOS DA GERAÇÃO DE EMPREGOS SOBRE A DESIGUALDADE DE RENDA: UMA ANÁLISE DA DÉCADA DE 2000}

\author{
Flavio Alex de Oliveira Carvalhaes, \\ Rogério Jerônimo Barbosa, \\ Pedro Herculano G. F. de Souza e \\ Carlos Antônio Costa Ribeiro
}

Palavras-chave: desigualdade de renda, expansão do emprego, ocupações

Nos últimos vinte anos, o Brasil viveu um período de contínua queda da desigualdade, especialmente relacionada aos rendimentos do trabalho. Pretendemos compreender como esse movimento se relaciona a uma dimensão pouco mobilizada no debate sobre o tema: a estrutura ocupacional. De início, apresentamos uma discussão e dados que descrevem as mudanças dos novos empregos gerados em dez anos (2002-2012). Em seguida, estudamos a desigualdade de renda do trabalho e seus componentes de duas maneiras: descrevendo a importância de componentes ocupacionais a cada ano; analisando especificamente sua queda $e$ o componente ocupacional se comportou diante de outras características, como raça, gênero, região e sobretudo escolaridade. Nossos resultados apontam para a relevância da estrutura ocupacional de acordo com as diferenças entre e dentro das ocupaçōes; indicam ainda que os recentes ganhos salariais dos trabalhadores e a queda da desigualdade de renda do trabalho não estiveram associados a mudanças na hierarquia e a aspectos da estrutura ocupacional. Em síntese, as discussōes e análises do artigo contribuem para um aspecto profundamente estrutural da desigualdade de renda no Brasil, e importantes para a análise sociológica, que são os fatores institucionais e do mercado de trabalho.

\section{THE IMPACTS OF EMPLOYMENT CREATION AND THE INCOME INEQUALITY: AN ANALYSIS OF THE DECADE OF 2000}

\author{
Flavio Alex de Oliveira Carvalhaes, \\ Rogério Jerônimo Barbosa, \\ Pedro Herculano G. F. de Souza and \\ Carlos Antônio Costa Ribeiro
}

Keywords: Income inequality; Earnings inequality; Job expansion; Occupations; Occupational structure

Income and earnings inequality have fallen consistently in Brazil in the last 20 years. In this article, we intend to understand how these trends are associated with the country's occupational structure, an overlooked dimension in the Brazilian debate concerning the theme. Our discussion starts with a detailed analysis of the pattern and quality of the jobs created between 2002 and 2012 in the country. This discussion draws the background to the following theme we address, which is the earnings inequality trend in the same period. We scrutinize the trends in two different ways. The first is a decomposition our chosen inequality index year by year. Second, we put into focus only the inequality decrease and how it is associated with the occupational component and other characteristics such as race, gender, region and education. Our results highlight the importance of the occupational structure, with its between and within occupations components accounting for more than half of the inequality observed in each year. Despite this importance, the occupational structure has a minor influence in relation to the fall of inequality, which is more associated with changes related to education. These results show that the significant changes that occurred in the Brazilian labor market in the last ten years were not associated with changes in the occupational structure. We demonstrate that differences between and within occupations have remained stable. Our results and analyses contribute in a non trivial way to highlight the structural quality income inequality in Brazil, pointing to the institutional factors associated with it through a sociological interpretation.

\section{LES IMPACTS DE LA CRÉATION D'EMPLOIS ET L'INÉGALITÉ DE REVENU: UNE ANALYSE DES ANNÉES 2002/2012}

\author{
Flavio Alex de Oliveira Carvalhaes, \\ Rogério Jerônimo Barbosa, \\ Pedro Herculano G. F. de Souza et \\ Carlos Antônio Costa Ribeiro
}

Mots-clés: inégalité de revenu, expansion de l'emploi, occupations

Au cours des vingt dernières années, le Brésil a vécu une période de chute continue de l'inégalité, liée particulièrement aux revenus du travail. Nous tentons de comprendre comment ce mouvement se rapporte à une dimension peu mobilisée dans le débat sur cette question: la structure occupationnelle. Initialement, nous présentons une discussion et des données qui décrivent les changements des nouveaux emplois créés en dix ans (20022012). Nous étudions ensuite, de deux façons, l'inégalité de revenu du travail et ses composantes: en décrivant, année par année, l'importance de composantes professionnelles; en analysant spécifiquement sa chute et le comportement de sa composante professionnelle face à d'autres caractéristiques, telles la race, le genre, la région et, surtout, la scolarité. Nos résultats indiquent l'importance de la structure occupationnelle conformément aux différences entre et à l'intérieur des occupations; ils indiquent aussi que les gains salariaux récents des travailleurs et la chute de l'inégalité de revenu du travail n'ont pas été associés à des changements dans la hiérarchie et aux aspects de la structure professionnelle. En bref, les discussions et les analyses de l'article contribuent à un aspect profondément structurel de l'inégalité de revenu au Brésil. Ils sont également importants pour l'analyse sociologique, qui sont les facteurs institutionnels et du marché de travail. 